\title{
Implemented Instructional Models in Tanzania: Experiences from Selected Higher Education Institutions
}

\author{
American Journal of Education and \\ Learning \\ Vol. 4, No. 1, 84-97, 2019 \\ e-ISSN:2518-6647

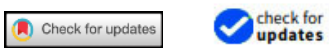

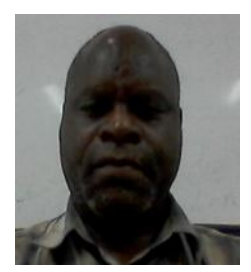

( Corresponding Author)

\author{
Bryson D. Kinyaduka ${ }^{10}$ \\ Perpetua J. Kalimasi ${ }^{2}$ \\ Anja Heikkinen ${ }^{2}$
}

Faculty of Social Sciences, Department of Education Foundations and Teaching Management Mzumbe, Morogoro, Tanzania. :Email:bdkinyaduka@mzumbe.ac.tz sEmail:pjkalimasi@mzumbe.ac.tz

${ }^{3}$ Professor School of Education, 33014 Tampere University, Finland ${ }^{3}$ Email:anja.heikkinen@tuni.fi

\section{ABSTRACT}

The purpose of this study was to explore norm (standard) instructional models for institutions and professors, implemented instructional models and factors which resulted in implemented instructional models ${ }^{1}$. This study used a case study research design, specifically multiple case study design. This study used observation, semi-structured interviews and documentary review to collect data. This study involved nineteen professor participants. In this study, data analysis was aided by the ATLAS.ti. Software. The Competence-Based Model (CBM) and Moderated Traditional Model (MTM) were norm instructional models in the two studied higher education institutions. Moreover, the CBM was the norm instructional model for professors in the two institutions. The institutions were the Mwalimu Nyerere Memorial Academy (MNMA) and the University of Dar es Salaam (UDSM). The implemented instructional models were Elusive Competence-Based Model (ECBM) or Mild Traditional Model (MiTM), the Elevated Traditional Model (ETM) and the Concentrated Competence-Based Model (CCBM). A number of factors contributed to implemented instruction models. Three main factors were indentified, namely poor economic conditions, poor instructional culture and inappropriate professor's professional intuitions and qualities. Two norm instructional models were identified, but their implementation was inadequate; the inadequate implementation was attributable to aforementioned factors. The study recommends pilot implementation of educational innovations before their scaling.

Keywords: Instructional models, Higher education institutions, Norm instructional models, Implemented instructional models, Elusive competence-based model, Mdoerated traditional model, Elevated traditional model.

DOI: $10.20448 / 804.4 .1 .84 .97$

Citation | Bryson D. Kinyaduka; Perpetua J. Kalimasi; Anja Heikkinen (2019). Implemented Instructional Models in Tanzania: Experiences from Selected Higher Education Institutions. American Journal of Education and Learning, 4(1): 84-97.

Copyright: This work is licensed under a Creative Commons Attribution 3.0 License

Funding: This study received no specific financial support.

Competing Interests: The authors declare that they have no competing interests.

History: Received: 21 January 2019/ Revised: 1 March 2019/ Accepted: 9 April 2019/ Published: 3 June 2019

Publisher: Online Science Publishing

\footnotetext{
${ }_{1}^{1}$ These are instructional models which are in actual operation in a given institution or programme; they can be norm (standard) instructional models or modified instructional models
} 


\section{INTRODUCTION}

The question on how students learn and on how to create learning environment and experiences is not a new phenomenon the world over, or rather in the teaching profession. For centuries now, teaching and learning processes have been taking place meanwhile deliberate efforts to improve the processes to meet the needs of society have been underway. While teaching and learning has a long history, especially, relating on how students learn, in many respects teaching and learning can be understood in two main perspectives, namely the passive perspective and the active perspective. This means a teaching and learning theory or model is likely to fall under one of the two perspectives. To clarify, there might be hundreds of teaching and learning models, but they can be clustered into two, i.e. the passive instructional models and the active instructional models.

While the two ways of creating learning environment and experiences are not new, in recent years, there has been a resurge of research striving toward understanding the two teaching and learning models as they relate to learning outcomes. The focus had been mainly on the instructional model in operation and how it contributes to academic achievement and development of selected learning outcomes. Many of these studies have been in nondegree higher education institutions and a few of them have focused on higher education institutions conferring degrees. In this paper, the Traditional teaching and learning model stands for the passive instructional model and the competence-Based Model (CBM) stands for the active instructional model.

As far as literature is concerned, it is obvious education systems widely accept the CBM as the best inatructional model for developing a number of skills believed to be mostly needed in the twenty-first century industries (Fulmer and Yeo, 2014). For example, the CBM is believed to have ability to develop creativity; cooperation; lifelong learning orietnation; problem-solving skills to mention but a few (Lee, 2014; Evans and Vander, 2018). Despite the important of the instruction model in developing the most important skills in the twenty-first century, substantial evidence (Meena, 2009; Sablonnière et al., 2009; Struyven and Meyst, 2010; Dasmani, 2011; Rahman et al., 2013; Kavindi, 2014; Luambano, 2014; Mtitu, 2014; Paulo, 2014; Kavacevic and Akbarov, 2016; Kazemi and Soleimani, 2016; Nzima, 2016; Plessis, 2016; Ishengoma, 2017) shows the implementation of the CBM in many countries has been superficial. As we will see soon, some of these scholars have been able to establish factors which have resulted in superficial implementation of the CBM whereas others have not been able to do so.

Indeed, half of the above studies have been conducted in Tanzania non-degree programmes and at lower levels of education. The rest of the above studies have been conducted out of Africa and have yielded similar results on the implementation of the CBM. As such, some scholars have been able to establish factors determining teachers' choice of instructional models, for example, Lindgren (1959) pinpoints traditions, theories and experience as factors that determine a teacher's choice of a teaching method. Again, Marton (2012)in the Variation Theory identifies the factors determining choice of instruction model as learning objective; freedom to choose teaching principles from whatever instructional model; experience; difference in understanding between a teacher and student; and tendency of human being to focus on one thing at a time.

In addition, Struyven and Meyst (2010) assert varied interpretation of the CBM resulted in different implementation, and therefore, teachers had varied practices. Furthermore, Dasmani (2011) in a study conducted in Ghana mentions lack of facilities, resources and poor connections between an institute and industry were bottlenecks toward implementing the CBM. This means there are fewer places to place students for practice and there are scarce resources and facilities. More importantly, Jabbour (2013) in a study conducted in Lebanon mentions scarcity of resources; overcrowded classrooms; standard curriculum and examinations; low motivation of school leadership; and lack of continuous professional development among teachers were setbacks in implementing 
the CBM. A group of scholars (Rahman et al., 2013) claim the newness of the CBM resulted in variation in assessment methods among teachers. This implies an innovation requires orientation for all implementers (teachers) to have shared understanding. At the same time, Sanchez and Hoyos (2014) claim the CBM is suitable for teaching some of subjects, and it is inappropriate for teaching other subjects. From this, a teacher may choose to use a particular instructional model based on the nature of a subject.

In other contexts, teachers are not ready to share teaching methods recommended for the CBM (Nissilä et al., 2015). This tendency may result in some teachers not to use the recommended methods because they are not well versed on them. In the same way, in central Asia, students, teachers and institutions agree that the CBM results in better outcomes (Sablonnière et al., 2009). This implies the CBM results in better outcomes. As such, this can be one reason for some teachers to go for it. Surprisingly, the teachers in Asia do not apply it and reasons are not established. In Tanzania, Meena (2009) claims more often than not teachers are left to interpret educational innovations, which results in multiple interpretations, of course, this in turn results in different standards in implementation. To add, Ishengoma (2017) mentions lack of funds as a factor hindering implementing CBM in studied higher education institution.

Moreover, Paulo (2014) claim teachers from tertiary teacher colleges have sound foundational knowledge about the CBM, but they do not apply it in classroom settings; this scholar does not identify the causes for the practice. Although, the factors that culminate in teachers going for one model over the other in classroom settings have been mentioned inadequate information is available on why higher education institutions in Tanzania would go for traditional instructional model in context whereby the norm instructional model is CBM. This is important to understand because in recent years the Tanzania Commission for Universities (TCU) has been encouraging universities to develop programmes based on the CBM. This study seeks to find out whether or not there are some other factors different from those in the theory by Marton (2012) by Lindgren (1959) and other scholars whose works are reviewed which act as setbacks in implementing the norm instructional model, CBM in higher education in Tanzania. To have a better understanding, this study raises three questions: what are norm instructional models for institutions and for professors in studied higher education institutions in Tanzania? What are implemented instructional models in studied higher education institutions in Tanzania? What factors have resulted in implemented instructional models in Tanzania studied higher education institutions?

\section{METHODS}

This study used a case study design, more specifically a multiple case study design. This design was adopted because the study wanted in-depth understanding about factors that resulted in implemented instructional models in selected higher education institutions. In this study, participants were professors and quality assurance officials. Nineteen participants were involved in this study in the interview sessions. The participants were selected based on their experience and participation in teaching selected programmes. In addition, background of a professor was important, for example, professors who were experts in competence-based teaching and learning were included first. The assumption was that they had richer data on the issue under study.

The selection of programmes for this study was purposive, superficially deviant case sampling. The programmes selected were those with teaching subjects the researcher was familiar with. This would help the researcher to know the relevance of teaching methods the professors used in classes. Also, the researcher would be at comfortable zone and with interest be able to follow what was really happening in classes. This would increase the validity and reliability of data collected. 
This study employed a number of data collection methods in order to cross-check consistency of findings based on methods of data collection. The methods used in this study include interviews, specifically semi-structured interviews. Semi-structured interview was used in order to solicit more information from participants when necessary do so. Another method used for data collection was observation. The researcher used both participant observation and unobtrusive observation. Participant observation was used to collect data from small classes of less than forty students, mainly seminar sessions whereas unobtrusive observation was used to observe classes which had over forty to over a thousand students. In such big classes, it was not easy for a professor to notice the presence of a researcher in a class. Observation and interview were used to collect data on implemented instructional models. During observation, the researcher stayed in a class through the target session, from the beginning to the end. The researcher observed what a professor was doing in a given session, classroom environment and teaching methods used in a given session. In interviews, the researcher sought to understand the methods a professor participant used to teach; the methods the professor preferred to use (professor's norm instructional model) and why the professor used or did not use the preferred teaching methods. The interview session lasted for 20 minutes to 2.30 hours. This depended on the role of participant and time available to a given participant. For example, for most quality assurance officials' interview did not go beyond 20 minutes and for professors it was between 1 hour and 2.30 hours. Finally, documentary review was used to collect data for norm instruction models of institutions. In this regard, documents like curricula, timetables, programme documents and studied higher education institution websites were reviewed.

This study employed purposive sampling to select institutions to study, specifically deviant case sampling. For example, the MNMA was selected because its norm instructional model was clear from that institution website, which was the CBM. Since this was the official institutional applied instructional model in preparing bachelor level teachers, the researchers were curious to know whether or not the institution implemented effectively the CBM, and why they managed to do so while literature indicates the implementation of the CBM is shaky in many parts of the world. The UDSM was included in this study because it was the oldest higher education institution, and it was thus assumed that it had her own instructional model to be identified through practice and documentation in the institution. The purpose of selecting the two institutions was to compare classroom practices and see whether or not they aligned with the norm instructional model of each institution or professors themselves.

In this study, four programmes from the two higher education institutions were included. The programmes were selected purposively. Two were undergraduate programmes while the other two were post-graduate programmes. One undergraduate programme was selected from institution M2 because it had teaching subjects the researcher who collected data was familiar with, and it was assumed that it used the CBM. Again, a similar programme was selected from institution D with an assumption that it used a different instructional, MTM. Furthermore, one postgraduate programme was selected because it used an instructional model that was purely assumed to be the CBM while another programme was selected because it was assumed that it used the MTM. In addition, this programme was selected because it had a number of professors sharing in teaching the same course and therefore, it would be easier to collect enough data from this programme since professors are always busy, and therefore, it is difficult to reach them.

With regard to data analysis, it was done with the aid of ATLAS.ti. Software. The software helped the researchers to identify themes of data from interviews, observation and documentary review. The analysis followed the following steps: first data were written in a word programme. Second, the data were subjected to ATLAS.ti. Software in form of text for analysis. Third, the researcher read the data in the ATLAS.ti. Software to develop themes from the data. Fourth, the researcher clustered the developed themes into categories. Fifth, the researcher 
developed broad concepts on theme clusters. The concepts represented each of the clusters. In this way, the researcher moved from understanding phenomena in terms of specifics to general way of understanding phenomena. Table 1 shows the summary of the methods section.

\begin{tabular}{|c|c|c|c|c|c|}
\hline Research question & $\begin{array}{l}\text { Data collection } \\
\text { method }\end{array}$ & $\begin{array}{l}\text { Data analysis } \\
\text { method }\end{array}$ & $\begin{array}{c}\text { Expected } \\
\text { participants }\end{array}$ & $\begin{array}{c}\text { Reached } \\
\text { participants }\end{array}$ & $\begin{array}{l}\text { Percent } \\
\text { reached }\end{array}$ \\
\hline $\begin{array}{c}\text { What are norm } \\
\text { instructional models } \\
\text { for institutions and for } \\
\text { professors? }\end{array}$ & $\begin{array}{c}\text { Documents \& } \\
\text { semi-structured } \\
\text { interview }\end{array}$ & Content analysis & 33 participants & 19 participants & $58 \%$ \\
\hline $\begin{array}{l}\text { What are implemented } \\
\text { instructional models? }\end{array}$ & $\begin{array}{c}\text { Observation \& } \\
\text { Semi-structured } \\
\text { interviews }\end{array}$ & Content analysis & & & \\
\hline $\begin{array}{l}\text { What factors have } \\
\text { resulted in } \\
\text { implemented } \\
\text { instructional models? }\end{array}$ & $\begin{array}{l}\text { Semi-structured } \\
\text { interviews }\end{array}$ & Content analysis & & & \\
\hline
\end{tabular}

\section{FINDINGS}

This section presents findings based on questions raised in the introductory part of this paper. The questions are: what is the norm instructional model for institutions and professors in studied higher education institutions in Tanzania? What are implemented instructional models in studied higher education institutions in Tanzania? What factors that have resulted in implemented instructional models in studied higher education institutions in Tanzania?

\subsection{Norm Instructional Models in Studied Higher Education Institutions}

It is always assumed that each educational institution has its own philosophy of education which guides decisions on education in a given institution. A philosophy of education in an institution, ultimately, determines the instructional model applied in a given educational institution. From this understanding, it is assumed that studied institutions had instruction models which guided how learning environment and teaching methods were chosen. In this study, in institution M2, the CBM was the standard instructional model in that the institution was under the National Council for Technical Education (NACTE), which is an early adopter of the CBM as an innovation, and therefore, champions the use of CBM in Tanzania education system. The CBM was visible from the higher education institution website; it was clearly stated that the institution used the CBM as a standard instructional model. This was also seen in the curricular documents of a studied programme, which clearly showed that the CBM was the standard instructional model (MNMA, 2014). Surprisingly, in practice the institution did not seem to implement the CBM, but rather it appeared to implement what this study calls the Moderated Traditional model (MTM). The same instructional model some scholars call it Traditional model; however, this study sees it as not typical traditional but it is rather a form of MTM. In this instructional model, the instruction moves from lectures to seminar sessions. This study identified the meso-instructional models and micro-instructional models for lectures and seminar sessions. The details of these instructional models are presented in the next section. In the view of the above findings, institution M2 had two standard instructional models in the institution, namely the CBM and the MTM as a standard instructional model in the institution.

In institution D which was under the Tanzania Commission for Universities (TCU), the institution used the MTM for undergraduate and taught post-graduate programmes. For research degrees, the CBM dominated. The findings are very obvious from the time-table used in the programmes. The undergraduate programmes and some 
of post-graduate programmes showed that they moved from lectures to seminar session. This was the MTM in practice although at the time of data collection in 2017 this institution had already changed her programmes into CBM, but the teaching remained the same in many ways. What changed was the programme document; it changed from units system to credit system. To add, number of hours for each student tasks was shown in a programme matrix; however, the teaching in many ways remained the same, (lecture to seminar sessions). The standard instructional models in institution D were the CBM and the MTM.

In addition, the study was interested to know the instructional model which was the norm (standard) instructional model for professors. To know the norm instructional model for professors, the researcher asked professors to say what they thought was their belief about how students learn. The norm instructional model for professors in studied higher education institutions was the CBM. All professor participants had confidence on the $\mathrm{CBM}$ and they believed it was the best instructional model for them to use in training students in studied higher education institution. As some of professor participants said,

Well, personally my teaching is geared towards developing competences among learners, not only the learners but also my colleagues. So competence-based is a driving philosophy because at the end of the day we are not just teaching. The teaching is geared toward impact that is what we expect as a product of our daily practices. Personally, competence-based teaching is my philosophy of delivery (p2 M2, 23 January, 2018).

My philosophy of teaching is participatory or learner centred, and I believe that learning occurs when a learner is engaged and when there is scaffolding so that he or she can be able to construct his or her own meaning. This happens when the learner interacts with the external environment. That is my belief about how students learn (P2 D, January 2018).

\subsection{Implemented Instructional Models in Studied Higher Education Institutions}

The study was interested in the implemented instructional models in the institutions. To know the implemented instructional models, the researcher observed classes and seminar sessions to see what was really happening in classes. In addition, the researcher asked the professor participants about the dominant method they used in classes. In institution M2, the Elusive Competence-Base model (ECBM), or Mild Traditional Model (MiTM) were implemented. The ECBM and the MiTM were characterised by the use of lecture or modified lectures without seminar sessions conducted, but group and individual assignments were provided for students to have continuous assessment which would be combined with final university examination scores to evaluate students.

The Elevated Traditional Model (ETM) and the Concentrated Competence-Based Model (CCBM) were implemented instructional models. The ETM was characterised by lecture sessions followed by seminar sessions for some courses, and without seminar sessions in others. Also, they had individual and group assignments and they also had tests and final university examinations. As for CCBM, it was characterised by formative assessment without university examinations; individual assignments; authentic assessment; nearly all presentations by students and nearly all contact hours were meant for seminars. In the view of these findings, four implemented models came up, namely the ECBM, MiTM, ETM and the CCBM. These were models at meso-level (institutional level). The following paragraphs cover on implemented instructional models at micro-level (individual professor) as were generated from observations made during lecture and seminar sessions.

During lecture sessions observation, two lecture models were vivid, namely the Typical Traditional Lecture model (TTLM) and the Modified Traditional Lecture Model (MTLM). In the TTLM, a professor reads from 
his/her notes in form of softcopy or hardcopy, and then, he/she provides comments on his/her presentation, but he/she does not allow any question from students. in this lecture model, students listen and take some notes if they wish through the session.

With regard to MTLM, in this lecture model a professor teaches with assisted tools or technologies, hard or soft technologies to make oneself understood in classes. The MTLM has three types, namely Pseudo-activepassive-tech-powered model; passive-tech-powered model; passive-human-powered model and Pseudo-activehuman-powered model. In Pseudo-active-passive-tech-powered model, a professor poses questions, allows students to discuss and then projects slides to read and clarifies for students to understand. Normally, students' involvement in the learning process is less than five minutes. In the passive-tech-powered model, in this model a professor projects slides, reads from them and clarifies for students to understand. As for passive-human-powered model, a professor uses drawings or diagrams drawn by him/her on chalk-board to explain some concepts. Finally, Pseudoactive-human-powered model which involves a professor asking a few questions with no discussion or with a short discussion, but without technology used in a class, for example, with no slides projected.

In seminar session observations, two seminar models were evident, the passive-active seminar model and the active seminar model. The passive-active seminar model has two breeds. These are the presenter-participant centred seminar model and the presenter-professor centred seminar model. In the presenter-participant seminar model, presenters do their presentation while participants listen to them. Having presented, seminar participants i.e. students and professors ask questions and give comments to a presentation. At the same time, presenters answer questions and receive or argue against comments seminar participants provide. In this model, there is interaction between presenters and seminar participants.

In relation to presenter-professor centred seminar model, presenters do present while answering questions from a professor who uses a Socratic Method. The questions they answer are normally posed to them as they present to let them discover when they present wrong information. In the Socratic Method, the rest of seminar participants are silent all the time the professor and the presenters are in a heated discussion. In this seminar model, there is intensive interaction between presenters and a professor.

As for active seminar model, the whole class is usually active in that a professor and seminar participants are free to tease the presenters mainly through Socratic Method to help them discover their weaknesses. At times, the seminar participants may also realise that their understanding or rather schemata was a misconception, and therefore, they modify it accordingly (they learn). In this seminar model, the give-and-take process and presentation are concurrent. However, professors and students used this model occasionally.

\subsection{Factors Resulting in Implemented Meso-Level Instructional Models in Studied Higher Education Institutions}

The study was interested to know factors that culminated in implemented instructional models, the ECBM, MiTM, ETM and the CCBM. A number of factors resulted in implemented instructional models. As for the ECBM, MiTM and ETM, poor economic conditions of a country, institutions and individual professors resulted in the implemented models. Further, poor instructional culture resulted in the implemented instructional models and inappropriate professor's professional intuitions and qualities. For example, in relation to poor economic conditions of a country, as we may know, Tanzania is a low economy country, and therefore, the likelihood is that she cannot provide funds to construct classrooms and employ enough academic staff in higher education institutions. as one professor participant said, "it is difficult to implement the competence based teaching and learning partly because the government at some point stops employment permits of academic staff and they tell you to do what you can despite the increase of number of students; this is a bad policy what about quality" (P1 CoHU, March 2018). Not only that but also the poor 
economic conditions of institutions. As one professor participant said, "another setback to implement the CBM is shortage of resources, and they university has no funds to buy all the books we need, but sometimes it might not be a matter of lack of funds but allocation" (p3 CoHU, March 2018). Again, poor economic conditions of an individual professor act as a drawback toward implementing the CBM. This is because professors look for part-time teaching jobs or research projects despite being overloaded in their own institutions. As some of professors had the following to say:

Another thing I have very limited time; I have other responsibilities I am in charge of the department. From these responsibilities, I might be travelling from here and there, but also hunting other activities that can make myself economically strong. Other institutions out there use us as well; so we do part-time teaching somewhere else (P4M2, 3.1.2018).

we hear in primary schools teachers do not teach because they spend much of their time selling pastries in their schools; it is also here there are professors here do not teach at all they are always busy with research projects they do not teach; they are after money, but those of us who do not engage in such projects we are always here teaching, but nobody sees us as doing a good job, but those who are always doing research without teaching (P4 SoED, March, 2018).

Again, from the presented information above, there are a number of sub-factors acting as setbacks in implementing standard instructional models in studied higher education institutions. These sub-factors are related to economic standing of a country, institution or individual professor. Table 2 shows a summary of the sub-factors and clarification showing the intensity for each sub-factor through frequencies.

Table-2. Poor economic conditions sub-factors and frequencies.

\begin{tabular}{llc}
\hline Main factor & Sub-factors (effects) & Frequency(n) \\
\hline Poor economic conditions & Shortage of professors & $\mathrm{n}=4$ \\
& Inadequate infrastructure-classrooms & $\mathrm{n}=6$ \\
& Some professors do part-time teaching & $\mathrm{n}=3$ \\
& Engage in irrelevant research projects & $\mathrm{n}=2$ \\
& Inadequate time & $\mathrm{n}=5$ \\
& Lack of training & $\mathrm{n}=4$ \\
\hline
\end{tabular}

Source: Created by researchers through field data, 2018.

With regard to poor instructional culture, most of students and some of professors are not proficient in the language of instruction used in higher education in Tanzania. During observation, some of professors struggled to communicate with a lot of difficulties and in some cases students were unable to follow what they attempted to communicate and learn. This was evident during interviews as well. As some professors had the following to say:

Another thing is that, the competence-based model calls for interaction, and therefore, there is a problem of language of instruction. Students are not conversant with English language. As such, when they are required to present something to others the language of instruction tends to be a great barrier to achieve this object (P1M2, April, 2018)

However, there is something else, the language. This is something I have forgotten this is one of the main factors influencing the type of method you use; for example, you want to use discussion method not only the first year students; master's student it is not so bad because they have experience. If the students have poor language, that affects a lot. They have to contribute in English language, and they would prefer to use Kiswahili (P4 SoED, Aril 2018).

That is one, but the second thing, and now I am talking as a person from Kiswahili institute. In addition, this has been my argument all along. It is an absurd to continue teaching using a foreign language. 
Really, it is not only absurd, but it is cheating because we know this has never worked (P1CoHU, March 2018).

Poor reading culture among students and some professors was a drawback in implementing the CBM. This was clear from observation. In one of the lecture session in a post-graduate programme, MEMA, a professor remarked: “read now when you are here as students after here you won't have time to read." This remark was made when only two out of eight presenters were active in answering questions from a professor. Another professor in one of the sessions in the MEMA programme asked whether or not students read a book he gave them, but only two students out of thirty three said that they had read the book chapter.

In addition, during interview one professor said, "We have a problem of reading culture among students and professors; students do not want to read books they want to read slides from professors. From this, we have a policy for undergraduate students that one question in the final examination must come from a book to make students read books" (P3 CoHU, April 2018)

To add, the deeply rooted culture of using lecture method in higher education institutions act as a setback in implementing CBM. From this teaching tradition, professors are guided to offer lectures and then conduct seminar sessions, and therefore, some professors cannot do otherwise. In some instances, professors perceive students as empty headed. As some professors said,

This is not a place for questions; questions will be asked during seminar sessions, don't ask questions here; there are those who understand quickly and there are those who do not understand no matter how long you teach them they never understand. You can repeat thirty times yet they do not understand. So do not ask questions here (P CoHU, January, 2018).

They are not ready even to receive even some new ideas, and sometimes they take learners as people who are tabula rasa...they are conservative; therefore, this conservative orientation has been infringing the right of a learner to show out his/her potentials (P3M2, 16.12018).

From the above presented information, a number of factors are related to poor instructional culture that are ingrained in students or their professors which subsequently result in superficial implementation of standard instructional models in higher education institutions, particularly, the CBM. Table 3 provides a summary and clarifies more on sub-factors from the preceding text on poor instructional culture.

Table-3. Poor instructional culture sub-factors and frequencies.

\begin{tabular}{llc}
\multicolumn{2}{c}{ Table-3. Poor instructional culture sub-factors and frequencies. } & \\
\hline Main factor & Sub-factors (effects) & Frequency(n) \\
\hline poor instructional culture & Poor reading culture (student \& professors) & $\mathrm{n}=5$ \\
& Low proficiency in the language of instruction & $\mathrm{n}=6$ \\
& University teaching tradition & $\mathrm{n}=6$ \\
& Student reluctance to cooperate & $\mathrm{n}=2$ \\
& Background of students & $\mathrm{n}=5$ \\
& & $\mathrm{n}=24$ \\
\hline \multicolumn{2}{l}{ Frequency Total } &
\end{tabular}

Again, it was because of inappropriate professor's professional intuitions and qualities. Professors as experts in their specialised fields and teaching profession; they have their own professional intuitions and qualities which make them do their job in a professional way. It is well known that professors need to have competence in terms of ethics and theories about teaching and learning. Moreover, professors have to know pedagogies and contents of courses they teach. More importantly, professors need to be committed to do their job in a professional manner. In other words, professors decisions before and in classes teaching should be informed by research-based theories which in turn are guided by professional intuitions or rather their actions are informed by other sub-theories within the 
research-based theories. With no doubt, these qualities of professors help them make decisions about how to teach based on the nature of content; learning object; availability of quality teaching materials; assumed effectiveness of a teaching method; and will, commitment and motivation to implement the available educational innovation, for example, instructional model. These findings are supported by the following voices of professor participants:

Again, the nature of the subject matter of course like the course I am teaching about Education Media and Technology; it is meant to teach some audio-visual, visual media, printed media to mention a few. You teach them these so what? They must do practice on how to use them! So you try to see on how students can be involved on everything you teach. You tell them in this group make sure your work is well processed, and make sure the font size is of this size; make sure your work is double spaced. They do some different..., but as you direct them how to do it you are really integrating the application of technology. That is Educational Media and Technology, the course they are doing. As I told you, the course is meant to make you communicate effectively during teaching and learning. I was telling them yesterday that I was not happy to see students failing to follow instructions for this course. ... so as I told you, some marks have been deducted. We expect you to be very smart with effective communication; communicating through ... so you need to understand what was wrong. So the norm instructional model influences the choice of methods (P1M2, 16.1.2018). Another professor added, "When I choose a teaching method I consider the learning objectives and expected outcomes" (P1M2, 16.1.2018). Furthermore one professor said, "In addition, the availability of the resources and materials, this is because if you wanted them to read books and there are no books you will have to change the method" ( $\mathrm{P} 2$ SoED, 5 April 2018). Indeed, another professor said... but some of professors are a little bit incompetent when it comes to the issue conducting seminar sessions. However, they have no problem with lecture method. Therefore, we need to emphasise to them that we have shifted from traditional approach to teaching and learning to competence-based teaching and learning. We need to direct them what they should do in classes. To do this, sometimes we may need to have peer review sessions. For example, when I have a lecture, I invite another professors to come in my lectures to listen, and later on, they come with their suggestions, they tell me, okay improve this, improve that...(P3 SoED, March, 2018)

In the view of the above professor participants comments, when professors lack effective professional intuitions and qualities the likelihood is that they cannot implement the CBM in an effective way. Table 4 shows a summary of findings for inappropriate professor's professional intuition and qualities

Table-4.Inappropriate professor's professional intuitions and qualities and frequencies.

\begin{tabular}{llc}
\hline \multicolumn{2}{c}{ Table-4.Inappropriate professor's professional intuitions and qualities and frequencies. } & Frequency(n) \\
\hline Main factor & Sub-factors & $\mathrm{n}=3$ \\
\hline $\begin{array}{l}\text { Inappropriate professor's professional } \\
\text { intuitions and qualities }\end{array}$ & Nature of content & $\mathrm{n}=2$ \\
& & $\mathrm{n}=5$ \\
& Learning objective & $\mathrm{n}=8$ \\
& Will, commitment \& motivation & $\mathrm{n}=4$ \\
\hline & Assumed effectiveness of the instructional model & $\mathrm{n}=22$ \\
\hline Frequency Total & Quality of teaching materials &
\end{tabular}

\section{DISCUSSION}

Two standard instructional models are revealing in studied higher education institutions. This implies higher education institutions have standard instructional models which are either explicitly or implicitly defined. For 
example, the CBM in institution M2 is explicitly defined in institutional documents, but the MTM is implicitly defined as normative instructional model in both institutions, $\mathrm{M} 2$ and $\mathrm{D}$. At the same time, the CBM in institution $\mathrm{D}$ is implemented as an imposed instructional model in one programme which makes it a unique programme in terms of teaching and assessment in the institution, since it focuses on formative assessment as opposed to summative assessment, and it focuses on authentic form of assessment. Indeed, the TM as seen in the literature involves the instructional model that moves from lectures to seminar sessions (McLaren and Kenny, 2015). However, this study sees this as MTM rather than TM because it has a number of teaching strategies that do not warrant it to be the TM, for example, the use of individual assignment, project-based-assignmens, group assignments, and the presence of Teaching Practice (TP) for undergraduate students. .

As for individual professors, their norm instructional model is the CBM. However, most of them do not implement the instructional model, but in one master's degree programme in institution D which had six students. This finding is similar to those of scholars (Kavindi, 2014; Luambano, 2014; Mtitu, 2014; Nzima, 2016) who report teachers having good understanding of the CBM, but they do not practice it. This further implies the CBM can be implemented in an adequate way when professors are committed to their job and when circumstances allow. These findings contradict those from another master's programme in institution D in which professors used ETM though they had a few students, around thirty. The professors who used the CBM managed to justify the use of the model for postgraduate students in their department to the university management. From this, the professors were not implementing the university norm instructional model, but the professors' instructional model.

The norm instructional models are not implemented adequately. Instead, there are new (modified) instructional models which are implemented from each norm instructional model. This implies there is theorypractice gap in implementing the standard instructional models. These finding is in line with those of scholars (Meena, 2009; Sablonnière et al., 2009; Struyven and Meyst, 2010; Dasmani, 2011; Rahman et al., 2013; Kavindi, 2014; Luambano, 2014; Mtitu, 2014; Paulo, 2014; Kavacevic and Akbarov, 2016; Kazemi and Soleimani, 2016; Plessis, 2016; Ishengoma, 2017) who claim the implementation of the CBM was superficial. In contrast, the finding contradict those of De Guzman (2010) who reports teachers in Philippine used the CBM methods as was expected from them. Meta-analysis of these findings seems to suggest the existence of a "Reversed norm (standard) principle" in implementation science. This principle states always there are circumstances that hinder professionals from executing their obligations in accordance to expectations despite having everything they want in order to do so. It seems it is not always easy to implement innovations, plans, laws, code of ethics and what have you by hundred percent (also see Kinyaduka (2017)). However, what is important is to implement plans or innovations to a sufficient level. Intuitionally, sufficient implementation might lie between $90 \%$ and $95 \%$. This level of implementation is assumed to result in the expected outcomes of a respective innovation or plan in education. This further implies evaluators of educational innovations should be wary during evaluation in education systems. That is to say evaluators in educational innovation have to be aware of this principle, Reversed norm principle. Of course, probably, they are very aware about this principle since in the education system the grading in examinations, ranges from $\mathrm{A}, \mathrm{B}, \mathrm{C}, \mathrm{D}, \mathrm{E}$ and $\mathrm{F}$; here $\mathrm{F}$ is "failed" while the rest are passes. Though the grading system differs from one country to another, but they all seem to deliver the same message of the Reversed norm principle.

In addition, it is hard to imagine when results in many studies indicate the CBM has not been adequately implemented in many of education systems which have adopted it. However, countries and institutions continue to adopt the instructional model. One explanation for this trend is captivating expected learning outcomes from the instructional model. The question is, are the expected learning outcomes, such as development of lifelong learning attitude realised? This question will be answered in the next paper; however, a burning question why do we 
continue to adopt the instructional model if we know we cannot implement it? The answer for this question is speculated to be associated to influence of multinational and multilateral organisations influencing countries to sing their tune for complying countries to get funding in education or for some other reasons. This again requires researcher's attention.

Various factors have been identified as contributing to implemented instructional models. The factors are not in all ways the same when compared to those advanced by Lindgren (1959) and Marton (2012) and of course, those by other scholars. This implies factors affecting the implementation of a norm instructional model are not the same all over the world, in all institutions and to all individual professors. The factors are contextual and they seem to be determined by economic conditions of a country, institution and individual professor. In addition, instructional culture of a country's education system, institution and individual professor have a key role to play when it comes to implementation of instructional models in higher education. Moreover, a professor's professional intuitions and qualities may affect the way one chooses and implements the norm instructional model. indeed, Marton (2012) in the Variation Theory sees professor's intuitions and qualities as factors affecting the choice of instructional models, but the theorist does not see economic conditions as important factor that may result in going for a particular instructional model neither does the scholar mention culture as one of factor that may affect the choice of instructional model. Correctly, Lindgren (1959) identifies culture and professor's intuitions and qualities as important factors that may affect the choice of instructional models; however, this scholar ignores economic conditions as one of factors that may affect the choice of a teaching and learning model. Most of other reviewed studies seem to implicitly touch about economic conditions, but their focus is either unclear or they focus on institution poor economic conditions (see (Mtitu, 2014; Ishengoma, 2017)). However, the present study sees the poor economic conditions of a country, institution and an individual professor as one of factors affecting the implementation of the CBM as an innovation in higher education institutions.

\section{CONCLUSIONS}

The CBM and the MTM are norm instructional models in studied higher education institutions. Furthermore, the implemented instructional models are: the ECBM, MiTM, ETM and the CCBM. Indeed, a number of factors result in the implemented instructional models. The factors contributing to implemented instructional models are not universal, but rather are contextual. In that view, we expand the Variation Theory by Marton (2012) to the next level of theory by adding the concepts of economy and culture in the theory. Moreover, we add the concept of economy in the Lindgren (1959) understanding. Adding the concepts to the school of thoughts, it widens their scope in explaining the phenomenon in different contexts. Therefore, the choice of instructional model (methods) mainly depends on culture, economy and individual professor professional rigour (competence). As always, the severity, and so do the degree of effect of these factors is contextual.

\section{RECOMMENDATIONS}

It might be important for higher education institutions to clearly show the philosophy of education which guides their thinking about the purpose of education, how learners learn and how evaluation can be done in order to see that the purpose of education is realised. In that sense, each professor should know the philosophy behind teaching and learning in their institutions or departments.

It is always important to know key factors that may hinder the implementation of an educational innovation, and to take appropriate measures to address them in advance. This action in many ways is likely to result in success stories of innovations expected to be implemented. The best way to do it successfully is through conducting pilot 
implementation of an educational innovation in an effective way, and then, scale it to countrywide or to an entire institution when we already know the most important factors to consider during implementation given the context we are in. It should also be noted that despite the pilot implementation a hundred percent implementation of an educational innovation is unlikely because of the reversed norm principle discussed elsewhere earlier in this paper. However, the pilot implementation improves the implementation process, and therefore, in turn it improves the degree of implementation of an innovation; consequently, the attainment of intended educational outcomes.

\section{ACKNOWLEDGEMENTS}

Many thanks are extended to esteemed participants for this study; they used their scarce time to provide information we required. Again, many thanks are extended to author's whose works have been cited in this paper. Lastly, but not least, many thanks are extended to editors and reviewers of the journal whose work has helped in improving the quality of this paper.

\section{REFERENCES}

Dasmani, A., 2011. Challenges facing technical institute graduates in practical skills acquisition in the Upper East Region of Ghana. Asia-Pacific Journal of Cooperative Education, 12(2): 67-77.

De Guzman, M.F.D., 2010. Preferred student-centred strategies in teacher-education: Input to outcomes-based instruction. Asian Pacific Journal of Education, 3(1): 40-48.

Evans, C.M. and J. Vander, 2018. Competency-Based Education: Education Reform A primer. Available from https://www.researchgate.net/publication/324780787_Competency-

Based_Education_Educational_Reform_A_Primer [Accessed 14 January, 2015].

Fulmer, G. and J. Yeo, 2014. Assessing 2 1st-century skills: Key concepts, challenges, and examples. In: Leong, W.S., Cheng, Y \& Tan, K.H.K. (Ed. 2014). Assessment and learning in schools. London: Pearson.

Ishengoma, J.M., 2017. Incorporating the tuning approach in higher education curricular reforms and course design in Tanzania for enhancing graduates' competencies: Stakeholders' views. Tuning Journal for Higher Education, 5(1): 121169.Available at: https://doi.org/10.18543/tjhe-5(1)-2017pp121-169.

Jabbour, K.K., 2013. Issues that restrain teachers from adapting student-centered instruction in Lebanese school. Didactics of Language and Literature Education, 12(2): 85-96.

Kavacevic, E. and A. Akbarov, 2016. The elusive of learner-centred teaching. International Description of Complex System, $14(2): 212-222$.

Kavindi, A., 2014. The implementation of competence-based curriculum in certificate teachers colleges in Tanzania: The case of two teacher colleges in Mbeya. Master's Thesis, University of Oslo.

Kazemi, A. and N. Soleimani, 2016. On the relationship between EFL teachers' classroom management approaches and the dominant teaching style: A mixed method study. Iranian Journal of Language Teaching Research, 4(2): 87-103.

Kinyaduka, B.D., 2017. Why are we unable bridging theory-practice gap in context of plethora of literature on its causes, effects and solutions? Journal of Education and Practice, 8(6): 102-105.

Lee, K., 2014. Competency-based curriculum and curriculum autonomy in the Republic of Korea. IBE Working Papers on Curriculum Issues No. 12. Seoul: UNESCO-IBE.

Lindgren, H.C., 1959. Learning theory and teaching practice: What are the main sources from which we draw learning theories that affect our behaviour regarding education? Available http://www.ascd.org/ASCD/pdf/journals/ed_lead/el_195903_lindgren.pdf [Accessed 17 July 2015 ]. 
Luambano, B.S., 2014. The implementation of constructivist approach in competence-based curriculum: A case of geography teaching in selected secondary schools in Songea municipality. Master's Thesis, The Open University of Tanzania.

Marton, L., L., 2012. Variation theory and the improvement of teaching and learning. Kallered: Ineko AB, Gotbog's University.

McLaren, H.J. and P.L. Kenny, 2015. Motivating change from lecture-tutorial modes to less traditional forms of teaching. Australian Universities' Review, 59(1): 26-33.

Meena, W.E., 2009. Curriculum innovation in teacher education: Exploring conception among Tanzania teacher educators. Published Doctoral Thesis: ABO Academy University Press.

MNMA, 2014. Curriculum for higher diploma of education in geography and Kiswahili language. Dar es Salaam: Author.

Mtitu, E.A., 2014. Learner-centred teaching in Tanzania: Geography teacher's perceptions and experiences. Doctoral Thesis, Victoria University of Wellington.

Nissilä, S.-P., A. Karjalainen, M. Koukkari and P. Kepanen, 2015. Towards competence-based practices in vocational educationwhat will the process require from teacher education and teacher identities? CEPS Journal, 5(2): 13-34.

Nzima, I., 2016. Competence-based curriculum in Tanzania: Tutor's understanding and their instructional practices. Doctoral Thesis, Linnaeus University.

Paulo, A., 2014. Pre-service teachers' preparedness to implement competence-based curriculum in secondary schools in Tanzania. International Journal of Education and Research, 2(7): 219-230.

Plessis, A.D., 2016. Student-teachers pedagogical beliefs: Learner-centred or teacher-centred when using ICT in science classroom? Journal of Battic Science Education, 15(2): 140-158.

Rahman, A.A., N.M. Hanafi, M.M. Mukhtar and J. Ahmad, 2013. Assessment practices for competency-based education and training in vocational college, Malaysia. Science Direct, 112(7): 1070-1076.

Sablonnière, D.L.R., D.M. Taylor and N. Sadykova, 2009. Challenges of applying a student-centered approach to learning in the context of education in Kyrgyzstan. International Journal of Educational Development, 29(6): 628-634.Available at: https://doi.org/10.1016/j.ijedudev.2009.01.001.

Sanchez, E. and V. Hoyos, 2014. Relationship between curriculum knowledge of in-service Mexican teachers and statistics. Available from http://icots.info/9/proceedings/pdfs/ICOTS9_3F2_SANCHEZ.pdf [Accessed 19 October, 2015].

Struyven, K. and D.M. Meyst, 2010. Competence-based teacher education: Illusion or reality? An assessment of the implementation status in Flanders from teachers' and students' points of view. Teaching and Teacher Education, 26(8): 1495-15 10.Available at: https://doi.org/10.1016/j.tate.2010.05.006.

Online Science Publishing is not responsible or answerable for any loss, damage or liability, etc. caused in relation to/arising out of the use of the content. Any queries should be directed to the corresponding author of the article. 